\title{
EVALUATION OF ADAPTATION CAPACITY AND THE IMPORTANCE OF COMMUNICATION BETWEEN CHILDREN AND PARENTS WHO EMIGRATE
}

\author{
Maria-Antoaneta VASILESCU (STANCIU), \\ Faculty of Psychology and Educational Sciences, University of Bucharest, PhD student \\ Bucharest, Romania. \\ E-mail: maria-antoaneta.vasilescu@drd.unibuc.ro
}

\begin{abstract}
The article follows the case of a preteen with certain particularities (12 years old, a pupil of a school located on the outskirts of Bucharest), who is in the situation of abandonment by one parent and the other parent left for a period of time to work abroad. The present study aims to evaluate the adaptability available to it, as well as the communication modalities, in order to find a method through which to make changes at relational level and to improve the communication between the preteen left at home and the departed parent. The research methods by which the case study data were collected were: BASC 2 test, anamnesis, interview, observation, activity product analysis. The results of the study show that, in the process of improving the capacity of school adaptation, following the emigration of parents, an essential role is played by the communication with the departed parent, the time allocated, the technology used, the frequency of communication with him. At the same time, the conclusions of the research affirm the importance of paying special attention to the children left at home, taking into account the potential of their increased vulnerability and the high probability that certain emotional deficiencies will arise in their development.
\end{abstract}

Keywords: ability to adapt; communicate; audio-video technology; migration; children left at home;

\section{THE PHENOMENON OF MIGRATION AND THE CHILDREN LEFT BEHIND BY MIGRANTS, IN THE ROMANIAN AND EUROPEAN SPACE}

Following the phenomenon of migration from Romania from the perspective of the censuses of the last years it was found that Romania loses population due to the natural and negative migration increase. The phenomenon of migration is a socio-demographic phenomenon that is socio-economically conditioned. This phenomenon of migration arose due to the socio-economic situation of the country.

The migration landscape is dynamic and constantly changing. Parental migration and the health outcomes of children left at home have become an increasingly global issue. The phenomenon of migration was determined by economic, environmental, political or social conditions. 
Migration is defined as "the mass movement of some tribes or populations from one territory to another, determined by economic, social, political or natural factors" (Explanatory Dictionary of the Romanian Language, the second edition revised and added, 2012).

In the specialized dictionaries we find the term migration as designating "the phenomenon that consists of moving a lot of people, from one territorial area to another, followed by the change of domicile and/or the classification in an activity form in the arrival area" (Dictionary of Sociology, 1998, p. 351).

There are two forms of migration, namely: immigration which means the totality of entries and emigration represented by the totality of exits. Sociologists argue that any migratory act represents both the migratory act and the emigration act.

Immigrants are those persons who have foreign citizenship and have their habitual residence in Romania; emigrants are those persons with Romanian citizenship who have their residence in Romania and reside abroad.

After the process of our country's accession to the EU in 2007, the phenomenon of migration increased through temporary migration to more economically developed countries with the aim of improving the quality of social and family life as a whole.

More and more people who are in the category of vulnerable and poor population choose to emigrate, motivating that they leave due to the job shortage or very low economic incomes. Following these departures, the most affected are those who are left behind, namely children.

In the specialty literature, the phenomenon of economic migration manifests a significant increase due to the changes at the political level with the fall of the communist system and the breaking of the borders and due to the problems of economic nature and the industrialization which is in a continuous growth in countries such as East and South-East Asia.

In Romania, there is already a labor shortage in certain economic sectors due to the gap between labor market demand and supply, which has determined a large part of global migratory movements. The migration of Romanians is a relatively recent phenomenon, but with the political and economic changes this phenomenon is increasing.

According to the statistics from $2007,85 \%$ of the migrant population is represented by persons between the ages of 15-64, persons who fall into the active life of the labor market. This process leads to an increase in labor resources in the destination countries and thus contributes to lowering the cost of labor.

During three years, from 2010 until 2013, the dynamics of the international migratory population is discussed by a population of about 5 percent, from 221 to 231 million migrants.

Migration has become a necessary strategy to reduce poverty in households.

In 2013, the number of migrant workers increased. The children of migrants have thus become an increased target of socio-economic vulnerability. With the departure of the mother from the family, the children are redistributed in the care of the extended family, who require more attention.

Some migrant workers in urban areas are not registered as residents and thus cannot have public access to the health system, renting a stable home and access to the education system. 
Parental migration can improve the quality of life of children left at home through remittances sent with the primary goal of reducing poverty. If the financial situation of migrant parents worsens, the quality of life of children left behind decreases.

As a negative consequence of the migration phenomenon is the separation of the family. The most pronounced consequence on the child's development is the breakup of the family through divorce. The divorce itself does not affect the child as much as the conflicts arising from it regarding the custody of the child and the division of common property.

In addition, there are many underdeveloped rural areas where internet and mobile access are limited or non-existent. Thus, ties may be non-existent with departed parents, these aspects can have long-term effects on the child's development, even leading to the inability to establish relationships with adults (Chase-Lansdale, Cherlin and Kiernan, 1995; Peterson, 1993).

In the specialized literature, the effects of migration on children left at home have been discussed, but the environment in which the child lives after leaving the parents is of particular importance. In fact, it is not the departure of the parents that affects the children, but the framework that the parents offered and what they could offer, the deprivation of what a family environment offers them. If their presence is not lacking, it is replaced by something else, the fact that the parents are far away has no effect on the child's development. Either by leaving they did not suffer at all because those children were deprived of the emotional environment anyway and escaped the burden of the presence of their parents, or after leaving they entered a sufficiently compensatory family support environment.

What is important is the way the child is cared for and the relationship with the extended family.

The focus is on regular communication with the departed parent, which would reduce psychological costs and could maintain the role that parents play as authoritative figures, thus helping to reduce behavioral disorders and improve school results.

\subsection{The educational effects of separation from parents as a consequence of migration}

The effects of migration on the education system are mixed. From the perspective of the authors Brown and Park, it was found that school performance is closely related to household income (Brown \& Park, 2002). A large part of the income of the migrants is sent home to their family and with these incomes children can have higher access to education and thus they can improve their school performance.

Lack of parents and their supervision is likely to lead to poor school results, negative well-being, emotional and behavioral disorders.

Those who remain in the care of their grandparents are less motivated to support their children's studies and less interested in their school results. In the case of children from extended families, they were prevented from receiving education due to internal problems and the limited space they benefited from. In the specialized literature, in a survey made of 7600 children in 4th and 5th grade from over 74 schools in different areas of China, Ninxia and Qinghai Province found that lack of parents can reduce the score on math performance by $15,6 \%$.

The material resources of the family can contribute to the school success of the child through direct investment as well as in an indirect way through access to the education system that will allow the child a good cognitive development (Tufiş. A, 2007). 
In Romania, the situation of children with parents who have gone abroad presents a great deficit of the integration and support of these children first and foremost in the education system. Poverty, inability of the state system to ensure safety and violation of the rights of these children lead to the inability to prevent risk situations to which they are exposed with the departure of parents through temporary migration (Tufiss. A, 2007).

\section{ANALYSIS OF ADAPTABILITY AND THE IMPORTANCE OF COMMUNICATION BETWEEN CHILDREN AND PARENTS WHO EMIGRATE}

The departure of the parent to work abroad is perceived as a lack of supervision followed by the lack of affection of a developing child.

Poverty in early childhood leaves these children alone facing challenges that happen later. Most of the pre-adolescents remain in the field of action, of the act, unable to express their feelings through word because they did not receive this in their early childhood.

This preteen was left behind by the emigration of the father with the relatives from the extended family, in an apparently secure environment, and the relationship with the parents is limited to the audio-video contacts, the communication remains superficial, the experiences of the child can practically not be noticed and thus the relations are cooled, due to the low availability of parents working abroad, communication decreases (Panaitescu, 2019).

BN's parents work daylight abroad, they do not have the availability of an authentic communication, so there is a possibility that the preadolescent may lose a basis of trust that allows him to be open with his parents. Between the BN preteen and the father, it all comes down to a material exchange "If you are good, I will send you what you want, and if you have good grades as well". This exchange of communication remains at the level of material and rewards. The emotional insecurity that the preadolescent feels usually persists. Parents, especially those who have earned some money abroad, are stunned when they return home to enjoy what they have achieved, but they are amazed by the emotional cold of to these children and their lack of gratitude for the ungratefulness of the sacrifice the parents made.

It revolves around the idea of sacrifice, which is not at all constructive for building a parent-child relationship and for building trust. When the parent returns home, there is an emotional gap between him and the preteen remaining at home (Panaitescu, 2019). In preadolescents this wandering (of the faulty relationship between parent and child) ends up curling addictions, crimes, and in some cases they reach psychiatric centers in dramatic conditions because there is no possibility of verbal communication with them.

Very poor self-esteem is another problem, because everything is invested in a hypertrophied self-image that focuses only on the material appearance, on what is possessed. The evolutionary consequences of preadolescent development can be quite dramatic. There are children from vulnerable, disadvantaged social backgrounds, who are often abandoned or manipulated by the fragility of their parents' personality. There are children who go through situations of abuse, who reach critical states as a result of these abuses, ranging from labor exploitation to sexual partner replacements for fathers, to their use to obtain small material benefits by working for others or doing sexual services.

The problem faced by the Romanian society in the case of the children left at home are the mistreatment behaviors of the pre-adolescents who come from the fathers, because according to statistics, mothers are the ones who decide to leave more often and they often discover happiness at a distance and never return home, so that the lives of these children go through a situation of existential nightmare (Panaitescu, 2019). 
It is also observed in environments with a better material situation, a relational dynamic that can be at the origin of unhealthy relationships, schematically there is a continuous line between rewards, overprotection and emotional negotiation.

Sociological research in the literature examines the plurality of situations of emigrants who left their children in the care of other relatives or friends, this vision is fragmentary, in the light of these cases it is necessary for specialists to start from the problematic situations encountered to find prevention solutions.

It is essential to ensure a stable but especially welcoming living environment in the cases encountered, which offers these children a state of security, which is quite rare. Depending on the complexity of the situation, the evolution of children who are victims of separation from their parents or who are victims of total breakup by one or both parents, are very variable.

The child psychiatric clinic is faced with severe cases accordingly expressed by behavioral disorders that are the hallmark of depressive states, conversive disorders encountered in the nineteenth century due to lack of communication and expression, or pathological personality structures in children left at home by migrant parents, who have gone through situations of abuse or mistreatment, are often found post-traumatic stress syndromes and adaptation disorders (Panaitescu, 2019).

The problem of addiction is a widespread problem in such cases, on the one hand parents offer these means to children on their own initiative but often foster carers claim that they are advised to provide their children with these phones with internet access, without thinking as a result of the vulnerability of these children to the online universe. The neurological and mental vulnerability of the preadolescent leads to the development of addictions as well as to the development of emotional disorders and social adaptation as a result of attending certain sites or certain types of games (Panaitescu, 2019).

\section{RESEARCH METHODOLOGY Evaluation Objective:}

\section{The purpose of the evaluation is:}

- to check whether there is a general tendency to increase the relationship between the child left at home and the parent gone, given the guilt of the parents.

- to identify mental health and / or illness as well as the ability to adapt socially in order to improve communication with the parent working abroad relevant to BN.

\section{BASC test 2}

The behavioral evaluation system for children.

Using as interview research methods, observation sheet, adolescent BASC 2 selfassessment scale, children's assessment system-BASC 2 teacher-adolescent evaluation scale, BASC 2 structured development history.

\section{BASC test 2}

BASC 2 involves a multi-method approach containing several evaluation methods that can be used both together and separately. It contains two evaluation scales, one for 
teachers (TRS) included in the case analysis and another for parents. Through these scales, data on the observable behavior of the child can be collected (Reynolds et al. 2011).

Another scale of the test is the self-assessment applied in this case analysis (selfreport, SRP) through which the child can describe his feelings, emotions and perceptions about himself. It also contains a structured interview that refers to the history of personal development and an observation sheet in which you can record the directly observable behaviors during class hours (Reynolds et al. 2011).

"The test involves the way the subject is evaluated in different social contexts, as well as the way the teacher relates to him, targeting: school problems, internalization problems, inattention / hyperactivity, personal adaptation and a general composite score, the index of emotional symptoms. Testing emotional reactivity to certain stimuli and perceptions of oneself. The test facilitates the identification at the educational level of a multitude of emotional and behavioral problems "(Reynolds et al. 2011).

\section{Case study presentation:}

Name and surname: BN is 12 years old, male, is a student in the 5th grade, in a school on the outskirts of Bucharest. He is part of a broken family with divorced parents. Arriving at the school's psycho-pedagogical counseling office on his mother's initiative, he speaks openly about his family and his problems.

The child has two younger brothers, one of whom is a stepbrother. The family in which the child lived when the father left for Austria consisted of both grandparents, the father and the younger brother. They all lived in their grandparents' house.

The father, 35 years old, works in a factory in Austria and in the past he was an electrician. The mother, 34 years old, of Roma ethnicity, has a cohabitation relationship with a man who is a criminal. The mother never worked and the $\mathrm{BN}$ was left in the care of her paternal grandparents. The contacts with the mother are limited, she does not pay them any alimony, context in which the BN refuses to go out with the mother most of the time, considers that she does not care about him.

The father's presence and educational influence were moderate due to the fact that he had a disorganized work schedule for the child's needs. The father was a conscious presence only during the period when he was free several times a week. One can easily observe the low motivation of the preteen for involvement in the learning task, the motivation is an oscillating one, the father is not interested in the school situation, and the grandmother is involved occasionally. The level of aspirations is low, the father constantly tells him that "if your mother signs your paper, we will all leave and we will have a better life there in Austria". BN only thinks about the beautiful life he can ever have. He is not stimulated to be actively involved in the learning task, he has no role model. The father's first departure was two months after he separated from BN's mother for a period of two years. All members of the family knew and were aware of this.

$\mathrm{BN}$ is very attached to his paternal grandmother, a situation in which he did not deeply perceive his father's departure. The father told them that they are leaving to give them a better life. BN was filled with many gifts after his father's visit, after a period of absence of one year. The father stayed at home for a month around the holidays and then returned to work. Referring to the relationship between the departed parent and the preteen remaining in the country, communication had improved during the departure due to the frequency with which they communicated audio-video. The father's second departure was for a period of two 
years, during which time he did not return at all, but kept the communication with BN for a few days and were seen using audio-video technology. During all this time when he was working in Austria, his father created a new relationship with a woman of Romanian nationality who had no children and their relationship resulted in a child.

After two years, the father returned home with the new family to his parents' house where he left. The parents of these children played the role of grandparents and the father was a kind of brother or uncle who brought resources but he was never perceived as a father.

The father never came to the school counseling office because he did not have time. Regarding the counseling activity, the father sent the written counseling agreement.

The child does not have a social image of the role of the father, he is influenced by the father's relatives and tends to reject the natural mother, considering her guilty for the inability to leave the country with the father and the adoptive mother. The conflict situation between the father's family and the mother does not allow us to obtain significant data about the mother. Mother who, after the grandmother's reports, took the children after her divorce and three days after brought them back and left them at the gates of the house.

The fact that some amplified ideas were brought to his attention create his mother's guilt about the lack of physical presence between them, so the child came to blame his mother and did not want to see her even though he lives very close to her. He always rejects his mother, so his mother no longer wants to go out with him. He is deprived of the parents' affection, the father left and the mother is absent. Grandparents are not involved in school work. Both grandparents work until the evening.

The last time his mother came to school, she came during the class to take BN out of class. The teacher asked her to wait for the break, but she refused and wanted to force him out of class. Failing this, she protested and was taken out of school. From BN's stories we know that she sometimes passes in front of his house but she doesn't come inside at all. The child's parents never came to the counseling office and did not request information about the counseling process in which the preteen participates. In the case of the preadolescent family, they live in the paternal grandparents' house and the relationship with the biological mother is almost non-existent based only on the material side.

4.2. Following the application of the BASC 2 Adolescent Self-Assessment Scale, the following were highlighted:

Attitude towards school the subject of the study shows negative attitudes and feelings, bored with the school system.

In the relationship with teachers, he manifests typical, age-specific attitudes.

Atypicality indicates an above average number of strange behaviors and thoughts as well as lack of control over thoughts. seeking.

Seeking stimulation. The subject indicates typical levels of age-related stimulation

\section{School problems}

The place of control-the subject has a sense of control below average, is not controlled by any adult, weak interest of the adult in his school life. The social stress manifested by the preteen is within the normal limits, specific to the age. The level of anxiety and depression indicates their typical age-specific levels. 
The pre-adolescent manifests the feeling of maladaptation in a relatively large number, gives up easily, permanently feels the sense of failure. It does not present atypical manifestations of somatization, it presents age-specific manifestations.

\section{Internalization problems}

The pre-adolescent indicates attention problems, the score indicates problematic levels in paying attention to tasks as well as low ability to focus attention. He is hyperactive and has problematic levels of activity, he cannot stay in one place and he has moments when he becomes noisy.

\section{Adaptive scales}

Relations with parents. At the relational level, the preadolescent has a problematic relationship with the parents, the parents are divorced, the mother rebuilt her life and abandoned them, and the father went to work abroad. The child shows a lack of trust and closeness to them. Communication with the immigrant parent is not authentic.

Interpersonal relations. Social relations are poor, limited, the boy is not liked by all those close to him.

The pre-adolescent shows low levels of self-esteem, sometimes the desire to be someone else appears.

Self-confidence. The subject has below average levels of self-confidence, does not feel safe and is unable to make decisions.

Behavioral assessment system for children-assessment scale for teacheradolescent BASC 2

hyperactivity. The preadolescent obtains a high score of hyperactivity which indicates problematic levels of the activity, he can show haste in carrying out some activities or he can bother the others.

Aggression. It is obtained a score that indicates problematic levels of aggression and can manifest threats as well as hitting others.

Behavior problems. The score obtained indicates problematic levels of anxiety, the subject may manifest certain fears, emotionality.

Anxiety and depression has typical age-specific levels.

Somatization. The subject indicates problematic levels of somatization, it can be manifested by headache or generalized pain.

Attention issues. The subject indicates problematic levels in paying attention and can be distracted or easily given up.

Learning problems. Depending on the score, the subject may have problems in areas that involve reading / math.

Atypicality. The child can be easily confused.

Withdrawal. Indicates problematic levels of withdrawal and can be manifested by shyness.

\section{Adaptive scales}

The score obtained on the adaptability scale indicates problematic levels of adaptability and may show difficulties in adapting to change as well as difficulties in changing tasks.

Social skills and leadership. Indicates typical levels manifested by an ordinary child at this age.

Learning skills. Indicates below average levels of study skills, he may show poor study skills. 
Functional communication. Indicates below average levels of functional communication, the child may manifest inadequate answers to questions.

\section{CONCLUSIONS}

This study led to the identification and evaluation of the situation of a pre-adolescent who remained at home due to the parental migration in the care of paternal grandparents, who present emotional disorders with negative emotional attitudes towards the school, lack of stimulation and motivation in this regard. The emphasis is on the importance of the communication link between the preadolescent left at home and the parent who went to work abroad. Teachers, from BN's perspective, are not interested in his fate from what he said. The feeling of maladaptation emerges both from the BASC 2 evaluation system itself and from the results of the adolescent teacher evaluation scale. The scores obtained in tests indicate low levels of study skills due to the lack of parental involvement or of the parents in the school activity. In the child's vision, it presents the school as very boring. At the level of the cognitive component, the results are poor, which indicates a lack of stimulation and motivation in this regard.

Following the application of the BASC 2 test to preadolescents, action-related disorders at the adaptive level there is repeated postponement, systematic lack of punctuality at the beginning of various activities, various acts of indiscipline during their development (he is late for classes sometimes, does not perform his tasks, is aggressive in various ways with colleagues and sometimes with teachers).

He shows disinterest in school and has a low involvement in school tasks and his circle of friends does not trust him. At the level of cooperation, he shows selfishness and is slightly conflicted (he wants to be well, sometimes he feels ignored by his relatives), slightly aggressive behaviors (verbal or physical).

The preadolescent's self-esteem is low. He has moments when he would like to be someone else. Relationship with his family appears to be problematic, unreliable, keeping a distant relationship with them. Following the counseling sessions, the emotional instability was observed, the preteen during the discussions between reactions of obvious hatred and contempt for the biological mother, and the father appears to be his 'protector' whom he idolizes. It is recommended to advise the father when he returns to the country as well as the relatives (grandparents in whose care the preadolescent remained) as well as the authentic communication of the parents with the preadolescent, focused on his interests, socioemotional needs.

Educational deficiencies and the lack of a parent or both parents has destabilized the mental balance of the preteen, so parents need to focus more attention on family relationships.

Parents will be advised to get involved in the child's school life, following his / her motivation and stimulation in the learning process as well as in extracurricular activities with recreational character.

It will be considered counseling the caregivers regarding the presence of control over the Internet games and limiting them, staying away from temptations risking health and personal safety. Permanent emotional support of the child by his parents is highly recomended, providing a safe environment and continuing counseling sessions within the school in order to improve communication between the migrant parent and the preadolescent left at home. 


\section{REFRENCES:}

[1] American Psychiatric Association. (2013). Diagnostic and statistical manual of mental disorders (5th ed.). Washington DC: American Psychiatric Association.

[2] Arguillas, MJB, \& Williams, L. (2010). The Impact of Parents' Overseas Employment on Educational Outcomes of Filipino Children. International Migration Review, $44 \quad$ (2), 300319.https://doi.org/10.1111/j.1747-7379.2010.00807.x

[3] Anghel, RG, Botezat, A., Cosciug, A., Manafi, I., \& Roman, M. (2016). "International migration, return migration, and their effects: A comprehensive review on the romanian case". (10445): Institute for the Study of Labor (IZA).

[4] Antman, FM (2011). "The intergenerational effects of paternal migration on schooling and work: What can we learn from children's time allocations?”. Journal of Development Economics, 96 (2), 200-208. https: // dx. doi.org/10.1016

[5] Antman, FM (2012). "Gender, educational attainment, and the impact of parental migration on children left behind." Journal of Population Economics, 25, 1187-1214. https://doi.org/10.1007/s00148-012$0423-\mathrm{y}$

[6] Botezat A, Pfeiffer F. The impact of parental labor migration on left - behind children's educational and psychosocial outcomes: Evidence from Romania. The People of Space Place. 2019; e2277. https://doi.org/10.1002/psp.2277

[7] Baptized A., Pfeiffer F (2019). The impact of parental labor migration on left-behind children's educational and psychosocial outcomes: Evidence from Romania Population, Space and Place, 141 157.https://doi.org/10.1016/B978-0-12-804394-3.00007-3

[8] Bowlby, J. (1982). Attachment and loss: retrospect and prospect. American Journal of Orthopsychiatry, $52(4), 664-678$.

[9] Cadsby, CB, Song, F., \& Yang, X. (2019). Are "left-behind" children really left behind? A lab-in-field experiment concerning the impact of rural / urban status and parental migration on children's otherregarding preferences. Journal of Economic Behavior \& Organization. doi: 10.1016 / j.jebo.2019.04.007

[10]Cortés, R. (2007). Children and women left behind in labor sending countries: an appraisal of social risk, global report on migration and children. In UNICEF. UNICEF.

[11]De Hass, H. (2008). Migration and development. A theoretical perspective. IMI working paper 9. Oxford: International Migration Institute, University of Oxford.

[12]Mitrofan. N, Ion. A, Iliescu. D. (2011). Technical Manual for BASC-2: Child Behavior Assessment System. Bucharest: OS Romania.

[13] Kaplan \& Sadock(2007). Handbook of clinical psychiatry. III edition. Medical Publishing House.

[14]Liu, X., Zhang, Y., Song, A., \& Shi, J. (2013). "Meta - analysis on mental health of left - behind children". Chinese Journal of Child Health Care, 21, 68-70.https://doi.org/10.1111/jpc.14349.

[15]Panaitescu, A. (2019). Seminar "André Sirota" - children abandoned by parents working abroad. Course notes.

[16] Tomşa, R. (2011). Psychological implications of parents' economic migration on preteens. Focșani: Terra Publishing House.

[17]Toth, A., Munteanu, D., \& Bleahu, A. (2008). Analysis at national level of the phenomenon of children left at home by parents leaving for work abroad. UNICEF and Social Alternatives.

[18]UNICEF. (2006). The situation of children left without parental care as a result of migration. Study report. Chisinau.

[19]UNICEF, Representation in Romania. (2008). National analysis of children left at home by their parents going to work abroad. Buzău: Representation of Unicef Romania.

[20]Tao, X., Guan, H., Zhao, Y., Fan, Z., 2013. Mental health among left-behind preschool-age children: a preliminary survey of their status and associated risk factors in rural China. J. Int. Med. Res. 42, 1-10.

[21] Verza, E., Verza, FE (2017). Child Psychology, Bucharest: Trei Publishing House.

[22]Zhao, F., \& Yu, G. (2016). Parental migration and rural left - behind children's mental health in china: A meta - analysis based on mental health test. Journal of Child and Family Studies, 25 (12), 3462-3472. https://doi.org/10.1007/s10826-016-0517-3

[23]Zheng, Y (2016). "Psychological consequences of parental migration for left - behind children". https://doi.org/10.1016/B978-0-12-804394-3.00007-3 